\title{
Life cycle assessment of tailings management options: a conceptual case study in Western Australia
}

\author{
A Carneiro The University of Western Australia, Australia \\ AB Fourie The University of Western Australia, Australia
}

\begin{abstract}
The vast amount of waste produced by the mining industry, of which a large proportion is tailings, has the potential to cause numerous environmental problems, and represents a possible barrier to sustainability. Although the choice of a strategy for tailings management has historically been dictated primarily by technical and economic factors, the sustainability of the selected tailings disposal method is becoming increasingly important in decision-making. Life cycle assessment (LCA) has been widely adopted as an environmental systems analysis tool and can be used for evaluating the environmental impacts of mining and mineral processing operations from a life cycle perspective. In spite of its appeal, however, the application of LCA in the mining industry, especially in tailings management is still a work in progress. Aimed at addressing this research gap, this paper reports on the results of a cradle-to-grave LCA study carried out to investigate the environmental profile of two different tailings management options. A conceptual case study for the disposal of gold tailings in Western Australia as a slurry, or as filtered tailings, was considered. The environmental impacts of each option were assessed, environmental hotspots were identified, and cleaner production measures were suggested to improve the overall environmental performance of tailings operations in Australia. In the context of mine waste management, this paper ends with a discussion addressing the benefits and challenges of applying LCA as an environmental decision-support tool, providing more information to the decision-making process and facilitating better communication with stakeholders.
\end{abstract}

Keywords: tailings management, life cycle assessment, renewable energy, sustainable mining

\section{Introduction}

There is increasing pressure on the resources sector and regulators to deliver a sustainable approach to mine waste management, and to integrate strategies that will produce the best practicable option for the environment. The vast amount of waste produced by the mining industry, of which a large proportion is tailings, has the potential to cause numerous environmental problems, and arguably represents one of the most significant barriers to sustainability (Espinoza \& Morris 2017). A tailings storage facility (TSF) is often one of the major environmental liabilities of a mine site, and is amongst the most visible legacies of a mining operation.

Although the choice of a strategy for tailings management has historically been dictated primarily by technical and economic factors, the sustainability of the selected tailings disposal method is becoming increasingly important in decision-making. In the wake of recent catastrophic tailings dams failures and increasing scrutiny over tailings operations, the International Council on Mining and Metals (ICMM) has called for greater emphasis on the sustainability aspects of tailings management by (i) integrating sustainable development into corporate strategy and decision-making processes (Principle 2); (ii) pursuing continual improvement in environmental performance issues, such as water stewardship, energy-use and climate change (Principle 6); and (iii) contributing to the conservation of biodiversity and integrated approaches to land-use planning (Principle 7) (International Council on Mining and Metals 2016).

In order to attain a socially responsible and sustainable tailings operation, effective TSF closure, and continuous corporate environmental improvement, it is crucial to systematically assess the environmental impacts associated with the management of tailings from a life cycle perspective. Life cycle assessment (LCA), 
which is widely used as an environmental systems analysis tool can be used, and has the potential to help the mining industry to move towards more sustainable business practices. LCA supports the evaluation of the environmental impacts of mining and mineral processing operations, including the assessment of the environmental impacts of associated products and services over all the stages of their life cycle. The broad perspective offered by LCA makes it a powerful tool for the comparison of the environmental performance of various tailings management options, considering the intricate complexities of material and energy flows into and out of the environment. LCA can be particularly valuable when there is a need to take into account the environmental benefits that can be obtained through different tailings management practices and the implementation of cleaner production measures (Reid et al. 2007).

In spite of its appeal, however, the application of LCA in the mining industry, especially in tailings management, is still a work in progress. Previous LCA studies in the literature have investigated the environmental impacts of alternative tailings management scenarios (Reid et al. 2009; Song et al. 2017; Adiansyah et al. 2017), and compared the environmental performance of material handling systems in mining (Awuah-Offei et al. 2009; Erkayaoğlu \& Demirel 2016). However, a detailed analysis of the main inputs and outputs associated with tailings management at a mine site, and a systematic evaluation of the potential environmental impacts associated with them over all the stages of their life cycle have not been observed. Furthermore, within the publically available LCA studies performed in the mining industry, very little emphasis has been placed on the assessment of the environmental impacts associated with tailings management. In other words, most mining LCA studies consider the tailings as a direct emission (waste) to the environment, without taking into account the processes needed for the production and storage of the tailings (Durucan et al. 2006; Reid et al. 2007; Reid et al. 2009).

Aimed at addressing this research gap, this paper reports on the results of a cradle-to-grave LCA study carried out to investigate the environmental profile of two tailings management options. A conceptual case study for the disposal of gold tailings in Western Australia (WA) as a slurry, or as filtered tailings, was considered. The environmental impacts of each option were assessed, environmental hotspots were identified, and cleaner production measures were suggested to improve the overall environmental performance of tailings operations in Australia. In the context of mine waste management, this paper ends with a discussion addressing the benefits and challenges of applying LCA as an environmental decision-support tool, providing more information to the decision-making process and facilitating better communication with stakeholders.

\section{$2 \quad$ Methodology}

\subsection{Life cycle assessment}

The LCA methodology is described by the International Organization for Standardization (ISO) on environmental management (ISO 2006a, 2006b) as a technique that can be used to address potential environmental impacts throughout a product or service's life cycle from raw material acquisition through production, use, end-of-life treatment, recycling, and final disposal (i.e. cradle-to-grave, cradle-to-gate, gate-to-gate, cradle-to-cradle, or circular economy).

LCA relies on a step-wise approach that has the objective of estimating the environmental impacts associated with a product, process, or activity by identifying and quantifying energy and materials used and emissions and wastes released into the environment, and to evaluate and implement opportunities to effect environmental improvements. For this purpose, the LCA methodology involves the compilation of an inventory of relevant environmental exchanges over the entire life cycle of a product or service, and the evaluation of the potential environmental impacts associated with those exchanges. For practitioners of LCA, the ISO 14044 (ISO 2006b) details the requirements for conducting an LCA study, which follows a systematic, phased approach that consists of four main components (Figure 1): goal and scope definition; life cycle inventory ( $\mathrm{LCl}$ ) analysis; life cycle impact assessment ( $\mathrm{LCIA})$; and interpretation. 


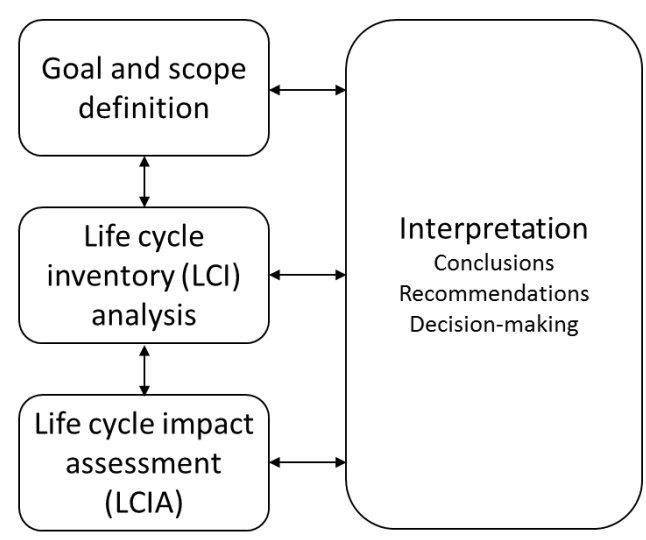

Figure 1 The main components of a life cycle assessment study

In the goal and scope definition phase, the aim of the LCA study is stated, the questions to be answered are formulated, and the scope of the study is defined, including its system boundary, which determines the unit processes that will be included within the analyses. It is also during this phase that the function to be provided by the product or service under study is identified and described quantitatively and qualitatively in the form of a functional unit (FU), e.g. produce and store a certain quantity of tailings over a certain number of years. The FU is the reference flow to which all other flows in the LCA model are related, and serves as the basis on which alternative options are compared.

In the $\mathrm{LCl}$ analysis phase, for each process included in the study, information is gathered on all relevant resource, material and energy consumptions and pollutants emitted associated with the system's delivery of the FU for the compilation of an inventory. Then, all these inputs and outputs are normalised to one FU and summed, generating the $\mathrm{LCl}$.

In the LCIA phase, the potential human and ecological effects of the resource, material and energy consumptions and the environmental releases identified in the $\mathrm{LCl}$ analysis phase are assessed. This is done by converting the large amount of resource extractions, energy usage and substance emissions listed in the $\mathrm{LCl}$ into a number of environmental impact scores using characterisation factors. For each flow in the inventory, there is a cause-effect chain that describes the relationship between the flow and the damages to the environment. Depending on the location of indicators in the cause-effect chain, the impacts can be characterised either at midpoint level, which focus on single environmental problems (e.g. climate change, eutrophication and ozone layer depletion), or at the endpoint level, which focus on the impacts on an area of protection, such as human health, natural environment and resources. The results can also be converted into one single score by using weighting factors (Dong et al. 2018).

Thus, LCIA helps the interpretation (fourth phase) of the LCA study by quantifying the environmental impacts, enabling the evaluation of the contributing factors from the production systems' life cycle, and the questions that were posed in the goal and scope definition phase to be answered. It is important to note that the way the results are categorised and presented depends on the impact assessment method selected for the LCA study, and the assumptions used to generate the results.

\subsection{Case study and tailings management options definition}

The case selected for this LCA study involves the management of a hypothetical, yet typical non-acid generating gold tailings stream in the Goldfields region of WA. Conceptual tailings project designs were developed for a mining operation based on an annual tailings production rate of $2 \mathrm{Mt}$, resulting in a total of $30 \mathrm{Mt}$ of tailings solids to be disposed of over the assumed 15-year operating Life-of-Mine (LOM). For the purposes of this study, tailings management included all the main activities associated with tailings in a mine site. It started with tailings dewatering at the mineral processing plant, going through tailings transport and discharge in the disposal area, TSF operation, surface water management, and final closure and rehabilitation 
of the TSF, including the post-closure environmental monitoring period required before closure is deemed acceptable and the land can be relinquished.

Two tailings management options were considered, namely OPT 1 entailing the management of slurry tailings at a solids content of $55 \%$ by mass, and OPT 2 entailing the management of filtered tailings at a solids content of $80 \%$ by mass (moisture content (geotechnical) of $25 \%$, where moisture content is defined as the weight of water as a percentage of the dry weight of the solids). The projects designed for both options assumed that the TSF will be constructed in a topographically flat terrain located $1 \mathrm{~km}$ away from where the tailings will be produced, and water required for mineral processing, i.e. make-up water, will be sourced from a catchment point located $5 \mathrm{~km}$ from the plant.

The project designed for OPT 1 considered that the tailings production process starts with the flocculation of the pulp using $30 \mathrm{~g} / \mathrm{t}$ of a synthetic polymeric flocculant, before being dewatered in a high-rate thickener made of steel mounted on a reinforced concrete slab. The slurry tailings, which were assumed to be the thickener underflow, will be transported to the TSF by five centrifugal pumps in series via a high-density polyethylene (HDPE) pipeline lined with carbon steel. Tailings will be deposited sub-aerially from a slurry ring main located on the TSF perimeter embankment, using a combination of spigots and conductor pipes at regularly spaced intervals.

Based on an assumed dry density of the deposited tailings of $1.4 \mathrm{t} / \mathrm{m}^{3}$, a paddock-type TSF was designed for OPT 1 with storage capacity of $21.5 \mathrm{Mm}^{3}$, and a total footprint area of approximately 94 ha. Major TSF infrastructure components included a $6 \mathrm{~m}$ high starter embankment, constructed with approximately $600,000 \mathrm{~m}^{3}$ of earthfill, an underdrainage system consisting of a pipe network and an underdrainage tower, and a decant structure comprising a decant causeway made of $54,600 \mathrm{~m}^{3}$ of earthfill, a decant tower, and two centrifugal water pumps.

Throughout the operating LOM, the electricity needed for the project will be provided via a connection to the WA grid, the TSF embankment will be raised to suit storage requirements, and make-up and decant water will be pumped to the plant for use within the process circuit. During operations, three potential environmental releases from the tailings deposit were considered: seepage of chemically affected water, dust emissions from the surface area of the TSF embankment, and a solid waste flow, i.e. the tailings that will remain in the environment at the end of operations.

At the time of closure, as tailings deposition ceases, the TSF will be left to dry for a period of three years, after which it was assumed trafficable for heavy earthmoving equipment to undertake rehabilitation work. This work will consist of capping the TSF with $578,623 \mathrm{~m}^{3}$ of mine waste rock, placing $148,475 \mathrm{~m}^{3}$ of topsoil over a total disturbed area of $97 \mathrm{ha}$, and deep ripping and spreading of $891 \mathrm{~kg}$ of seeds for revegetation purposes. Another period of 3 years was assumed for regulatory approval of the rehabilitation strategy. A post-closure environmental monitoring period of 10 years was considered to meet closure criteria and completion of the project's life. The assumption is thus that it will take 34 years from the start to the final relinquishment of the project designed for the management of slurry tailings (OPT 1).

The project designed for OPT 2 assumed the same tailings production process of OPT 1 , but considered that the slurry tailings will be fed into a filtration plant, where three filter press units will further dewater the tailings so they can be mechanically transported to the disposal area by an electric conveyor belt system. Beside the filters, which are made of steel and a considerable amount of polypropylene, the filtration plant will include ten pumps, four air compressors, three filter discharge conveyors, and two liquid storage tanks. Also differing from OPT 1 , the OPT 2 considered that the electricity needed for the project will be provided via a connection to the WA grid, which was assumed to run on $100 \%$ renewable (solar) energy.

Based on a dry density of the deposited tailings of $1.8 \mathrm{t} / \mathrm{m}^{3}$, a dry stack-type TSF with $4 \mathrm{H}: 1 \mathrm{~V}$ side slopes and capacity for $16.2 \mathrm{Mm}^{3}$ was designed for OPT 2, comprising a total footprint area of approximately 49 ha. Major TSF infrastructure components included a runoff diversion channel and a lined stormwater pond for the management of surface water. Throughout the LOM, collected precipitation runoff in the pond and make-up water from the borefield will be pumped to the plant for use within the process, and filter cloths will be replaced as required. At the disposal area, filtered tailings will be placed in the dry stack by a dozer, 
and progressive rehabilitation of the TSF will be undertaken concurrent to operations (i.e. once a dry stack lift of $20 \mathrm{~m}$ has been completed, its side slopes will be capped with topsoil and revegetated). During the TSF operational phase, dust emissions and a final waste flow (tailings solids) were considered for the purposes of this LCA study.

At the time of closure, the remaining reclamation of the dry stack will take place in the year after tailings deposition ceases. The total rehabilitation work of the OPT 2 project consists of backfilling the stormwater pond with $103,559 \mathrm{~m}^{3}$ of mine waste rock, placing 76,143 $\mathrm{m}^{3}$ of topsoil over a total disturbed area of 56 ha, and deep ripping and spreading of $653 \mathrm{~kg}$ of seeds for revegetation purposes. A period of one year was assumed for the regulators to approve the rehabilitation strategy, and a 10-year monitoring period to meet closure criteria and completion of the project's life was also considered. The assumption is thus that it will take 29 years from the start to the final relinquishment of the project designed for the management of filtered tailings (OPT 2). More details about the basis of design and assumptions made for this conceptual case study involving the management of tailings in WA can be found in Carneiro \& Fourie $(2017,2018,2019)$.

\subsection{Life cycle assessment of tailings management options in Western Australia}

The LCA study reported in this paper was conducted based on the methodology described by the ISO 14040 series LCA standards. The SimaPro software version 9.0.0.35 (PRé Consultants 2019) was used for LCl and LCIA modelling.

\subsubsection{Goal and scope definition}

The goal of this study was two-fold. Firstly, assessing the life cycle environmental impacts of the project designed for the management of slurry tailings (OPT 1), making a contribution analysis to identify environmental hotspots. Secondly, comparing the life cycle environmental impacts of OPT 1 and OPT 2 (management of filtered tailings), assessing the extent to which technology improvements for the dewatering and transport of the tailings, and the use of renewable energy affect the environmental performance of the tailings operation.

The adopted system boundary was from cradle-to-grave (Figure A1 in the Appendix). It begins with resource extraction, energy consumption, and estimated emissions for the production of all relevant material, machinery and energy needed, going through their transport to the mine site and use throughout the life of the project, until the end of the life of the considered inputs. Environmental releases from the TSF were also considered within the system boundary.

The function of this study was to manage the tailings production throughout the entire life of the project, from construction to relinquishment. The FU was specified as the total management of the tailings throughout the LOM, and the reference flow was therefore set as $30 \mathrm{Mt}$ of tailings solids from the mineral processing plant. The reason for choosing tailings management as the $\mathrm{FU}$ of this study was to make the alternative options comparable, and ensure that all the LCA standards are applicable (van Zyl 2008).

\subsubsection{Life cycle inventory analysis}

Two steps were undertaken in the $\mathrm{LCl}$ analysis phase. First, for each tailings management option, extensive data collection of relevant flows into and out of the designed project was carried out for the development of an inventory. Then, information compiled in the inventory was entered in SimaPro for modelling the LCl. Input data was linked to $\mathrm{LCl}$ databases available in the software, so the input/output flows of upstream processes could be considered in the LCA. The vast majority of the input data was linked to the Australian National Life Cycle Inventory Database (AusLCI) Unit Processes library as it has the most appropriate information with regards to time, geography and technology to suit the conditions in Australia (Grant 2016). When a unit process was unavailable in the local library, the ecoinvent v3.4 database was used.

The inventories prepared for this LCA study contain calculated quantities of natural resources (groundwater and land), machinery use, materials, energy, and the considered environmental releases from the TSF (to air 
and water, and final waste flow). They were estimated based on a comprehensive literature review, completed project designs, discussions with experienced people in the industry and government, field trips to various tailings dams, and to a filtration plant, all located in WA, and feedback received on previous peerreviewed papers published in the proceedings of international tailings conferences (Carneiro \& Fourie 2017, $2018,2019)$. Therefore, despite the fact that this study entails a conceptual case, collected data for the preparation of the inventories is inclusive of a relatively high level of detail. This is an advantage since a recognised challenge of conducting an LCA in the minerals industry is to gather all the applicable information needed for compiling a $\mathrm{LCl}$, and obtaining data in a format that is useful in the context of LCA is difficult, given that such data are often confidential (Durucan et al. 2006; van Zyl 2008; Reid et al. 2009; Norgate \& Haque 2010; Edraki et al. 2014).

For the purposes of organising the LCls to better appreciate key input/output flows and processes needed for tailings management, and how they contribute to the overall environmental performance of a tailings operation, inventory data was divided into eight different groups, namely plant and ancillary equipment, make-up water, flocculant, electricity, emissions from the TSF, seeds, land occupation, and earthworks. The main assumptions made when compiling the inventories for the assessed tailings management options are summarised in Table A1 in the Appendix.

\subsubsection{Life cycle impact assessment}

LCIA was performed using various midpoint impact categories drawn from four different impact assessment methods: Global Warming Potential (GWP) (Solomon et al. 2007), CML-IA (Guinée 2002), TRACI (Bare 2002), and USEtox (Kounina et al. 2014) methods. These impact assessment methods, along with the selected midpoint impact categories, were chosen because they were recommended by the Australian Life Cycle Assessment Society (ALCAS) for LCA studies centred on Australian products and processes in the document entitled Best Practice Guide for Mid-Point Life Cycle Impact Assessment in Australia (Renouf et al. 2018). This document provides guidance on the selection of appropriate LCIA methods that can convert and aggregate $\mathrm{LCl}$ data into indicators of impact using characterisation factors that, where possible, reflect the environmental conditions in Australia.

Nine midpoint impact categories were selected for this LCA study as they are the most applicable in the context of this case involving tailings management in WA:

1. Climate change impact category, which was analysed based on the GWP method. It accounts for the impacts of human activities on the climate due to the emissions of greenhouse gases (GHGs) to the atmosphere. Its result indicator is expressed in $\mathrm{kg}$ of carbon dioxide equivalent $\left(\mathrm{CO}_{2} \mathrm{eq}\right)$.

2. Mineral resource depletion impact category, which was analysed based on the CML-IA method. It is related to the extraction of minerals due to inputs in the system under study. It is expressed in $\mathrm{kg}$ of antimony equivalent (Sbeq).

3. Fossil fuel depletion impact category, which was analysed based on the CML-IA method. It is related to the extraction of fossil fuels due to inputs in the system under study. It is expressed in megajoule (MJ).

4. Ozone layer depletion impact category, which was analysed based on the CML-IA method. It covers the reduction in the ozone layer due to the emission of ozone-depleting substances to the atmosphere, such as chlorofluorocarbon (CFC) and other halocarbon releases to air. It is expressed in $\mathrm{kg}_{\mathrm{g}}$ of $\mathrm{CFC}^{-11}$ equivalent (CFC-11eq).

5. Eutrophication impact category, which was analysed based on the CML-IA method. It is related to the potential impacts of excessively high levels of macronutrients released into the environment, the most important of which are nitrogen $(\mathrm{N})$, phosphorus $(\mathrm{P})$, and organic compounds. It is expressed in $\mathrm{kg}$ of $\mathrm{PO}_{4}^{-3}$ equivalent $\left(\mathrm{PO}_{4}^{-3} \mathrm{eq}\right)$. Once released into waterways (aquatic eutrophication), macronutrients can increase algae growth, which may reduce sunlight infiltration and cause oxygen depletion affecting species composition, while when released to land (terrestrial 
eutrophication), they can lead to increased susceptibility of plants to diseases and pests. Moreover, emissions of nitrogen compounds to air due to fuel combustion can also contribute to eutrophication, making it a relevant category to be assessed in LCA studies (Renouf et al. 2018).

6. Particulate matter formation impact category, which was analysed based on the TRACI v2.1 method. It is related to airborne emissions with effects on human health, and accounts for particle concentrations in the air due to both primary emissions of particles and formation of secondary particles due to atmospheric chemical reactions. It is expressed in $\mathrm{kg}$ of particulate matter up to 2.5 micrometres in diameter equivalent (PM2.5eq).

7. Human toxicity (cancer) impact category, which was analysed based on the USEtox method with regionalised characterisation factors for Australia. It refers to the harmful effects of chemicals on human health, and takes into account the fate, route of exposure and toxicity impact of toxic substances when released into the environment. It is expressed in comparative toxic unit (CTUh).

8. Human toxicity (non-cancer) impact category, which was analysed based on the USEtox method with regionalised characterisation factors for Australia. It also refers to the harmful effects of chemicals on human health, and is expressed in comparative toxic unit (CTUh).

9. Freshwater ecotoxicity impact category, which was analysed based on the USEtox method with regionalised characterisation factors for Australia. It refers to the harmful effects of chemicals on individual species, and is expressed in comparative toxic unit (CTUe).

\section{Results and discussion}

\subsection{Life cycle inventory analysis}

A comparison of the LCls in terms of losses of natural resources shows that the project designed for the management of slurry tailings (OPT 1 ) was found to require a larger amount of land to be transformed and occupied for a certain time $\left(33,071,800 \mathrm{~m}^{2}\right.$.a), which is more than double the land use input required for the project designed for the management of filtered tailings (OPT 2) $\left(16,171,553 \mathrm{~m}^{2}\right.$.a). This is because the disposal of slurry tailings required a greater footprint, and a longer period of land occupation as the TSF was assumed to be left drying before becoming safe to start the rehabilitation work. Correspondingly, assuming a linear relationship between dust emissions and the slanted lateral surface area of the TSF embankment, the amount of fine particles released to air is also higher for OPT 1. Approximately 15,000 t of fine-grained material were estimated to be dispersed from the tailings deposit footprint throughout the operating life of the project designed for OPT 1, which is twice the dust emissions expected from the dry stack designed for OPT $2(7,277 \mathrm{t})$.

The consumption of make-up water (groundwater) is also higher for OPT 1. Once in the TSF, a considerable amount of this water is lost as entrained water in the interstices of the tailings, or through seepage and evaporation. Thus, despite consolidation water from the tailings and collected precipitation runoff in the decant pond becoming available for use in the process circuit, a considerable volume of make-up water still needs to be sourced from natural resources for mineral processing. It was estimated that OPT 1 will need $1.55 \times 10^{10} \mathrm{~kg}$ of groundwater, which is $283 \%$ more than the amount of water required for OPT $2\left(4.05 \times 10^{9} \mathrm{~kg}\right.$ of groundwater). For the purposes of this LCA study, seepage from the TSF was only considered for OPT 1. It was assumed as $10 \%$ of the total volume of the water discharged with the tailings, resulting in a total of $2.65 \times 10^{9} \mathrm{~kg}$ of chemically affected water released to groundwater resources throughout the operating LOM.

A comparison of the LCls in terms of the demands of earthmoving equipment throughout the LOM shows that the inputs associated with the operation of excavators and haulage trucks are higher (700\%) for OPT 1 , owing mainly (52\%) to the earthworks required for raising the TSF perimeter embankment to accommodate slurry tailings as they are produced. On the other hand, notwithstanding the minimum earthworks required for site preparation and construction of initial TSF infrastructure, throughout the life of the OPT 2 project, the input of dozer operations is higher (almost 500\%). This is due to the assumption that filtered tailings will 
be placed in a dry stack-type TSF by a dozer, which will be required to operate for approximately 40,000 hours.

In terms of materials and electricity demand, OPT 2 was also found to require higher inputs. It was estimated that more than $455 \mathrm{t}$ of steel is required for the thickener, the filters and the structural frame that will support the filtration plant, compared to $133 \mathrm{t}$ of steel for making the thickener and the tailings delivery pipeline for OPT 1. Moreover, approximately $519 \mathrm{t}$ of polypropylene will be required in the filters (filter cloths) throughout the operating life of the filtration plant. These also resulted in the input associated with the transport of materials and plant equipment to the mine site being higher (91\%) for OPT 2. Regarding energy consumption, the further effort of dewatering the tailings in a filtration plant and transporting the tailings via an electric conveyor belt system resulted in the electricity input of OPT 2 ( $84 \mathrm{GWh}$ ) being $25 \%$ higher than OPT 1 (67 GWh).

\subsection{Life cycle impact assessment}

\subsubsection{Life cycle environmental impacts of the project designed for the management of slurry tailings (OPT 1)}

The life cycle environmental impacts of OPT 1 based on the selected midpoint impact categories drawn from four impact assessment methods recommended by the ALCAS, such as GWP, CML-IA, TRACI, and USEtox methods are illustrated in Figure 2, and the results are presented in Table A2 in the Appendix. Electricity consumption dominated six of the nine midpoint impact categories assessed in this LCA study, contributing $78 \%$ to climate change, $63 \%$ to mineral resource depletion, $73 \%$ to fossil fuel depletion, $61 \%$ to eutrophication, $38 \%$ to the human toxicity (cancer), and $86 \%$ to the freshwater ecotoxicity impacts.

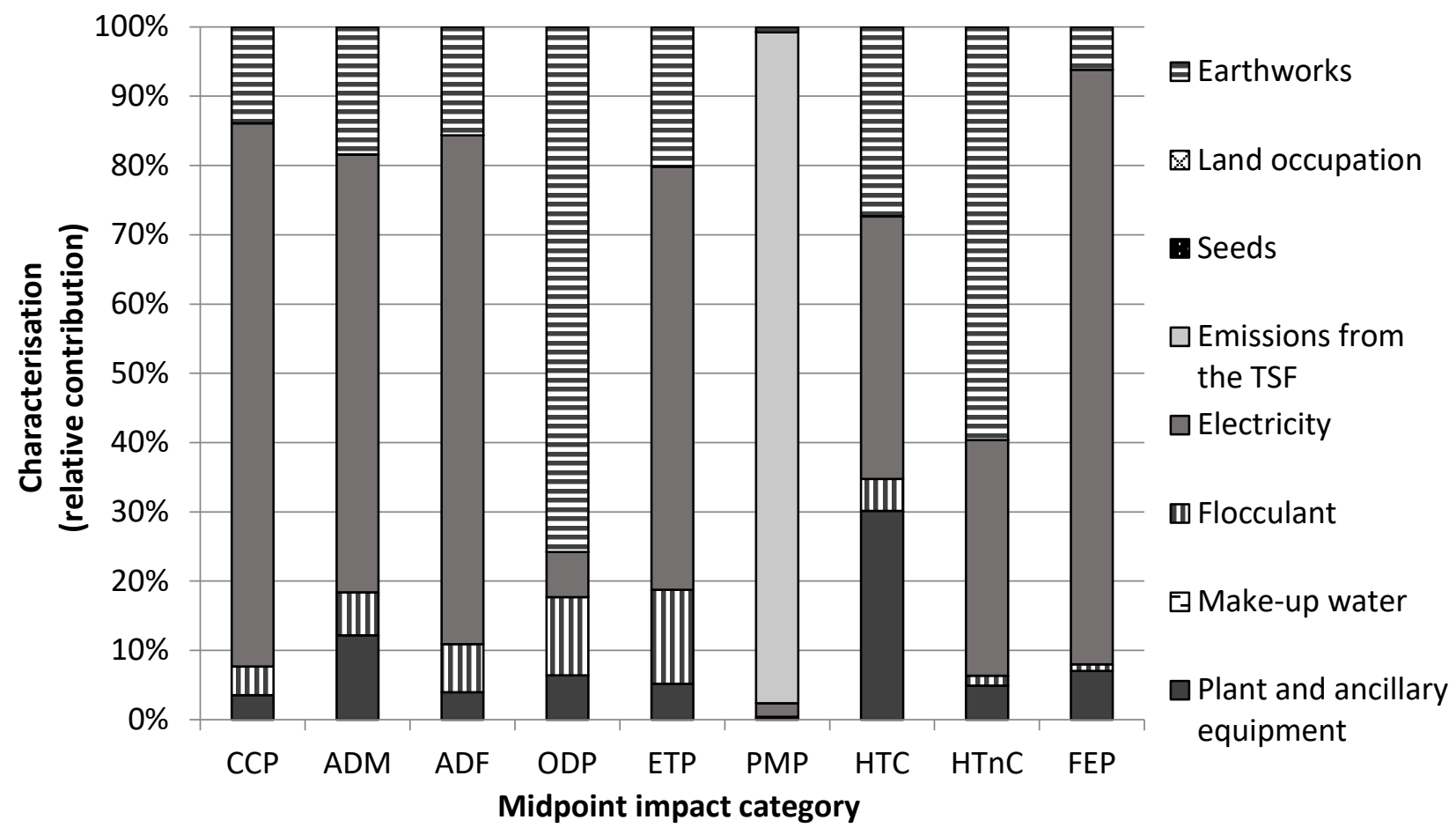

Figure 2 Life cycle contribution analysis of the project designed for the management of slurry tailings (OPT 1) based on selected midpoint impact categories drawn from four impact assessment methods (GWP, CML-IA, TRACl, and USEtox) ${ }^{a}$. ${ }^{a} C C P=$ climate change; $A D M=$ mineral resource depletion; $A D F=$ fossil fuel depletion; $O D P=$ ozone layer depletion; $E T P=$ eutrophication; $\mathrm{PMP}=$ particulate matter formation; $\mathrm{HTC}=$ human toxicity (cancer); $\mathrm{HTnC}=$ human toxicity (noncancer); $F E P=$ freshwater ecotoxicity 
The results of a process contribution analysis showed that processes associated with the generation and distribution of electricity required throughout the life of the project, of which $73 \%$ is needed for pumping the slurry tailings to the TSF (Figure 3), contributed the most to these environmental impacts. The carbon footprint of OPT 1 was estimated as $6.4 \times 10^{7} \mathrm{~kg} \mathrm{CO} \mathrm{CO}_{2} \mathrm{eq}$, with the dominant contributors being the GHG emissions resulting from the burning of fossil fuels to produce electricity. According to the AusLCI database available in the SimaPro v9 software, the average WA electricity mix (in 2017) consisted of $48.7 \%$ of black coal, $43.1 \%$ of natural gas, and smaller amounts of oil and renewable energy (3.7\% wind and $3.2 \%$ solar).

The use of coal and natural gas to generate electricity was also found as the primary contributor to the depletion of fossil fuels, while emissions from the coal-fired power plant were found to dominate the eutrophication impact, and the use of minerals in the process of manufacturing solar-powered photovoltaic (PV) panels, which are needed to generate solar energy was found to be the biggest contributor to the depletion of mineral resources.

The disposal of slag from the steel-making process, which results from the upstream processes associated with the manufacturing of earthmoving machinery and plant and ancillary equipment, was found as the main contributor to the human toxicity (cancer) impact. However, electricity consumption dominated this category due to the combined impacts caused by the disposal of sulfidic tailings, which are generated when beneficiating copper ores to produce the copper that is needed in the electricity distribution networks, and the disposal of coal ash at the coal-fired power plants when generating electricity, which was also found as the primary contributor to the freshwater ecotoxicity impact.

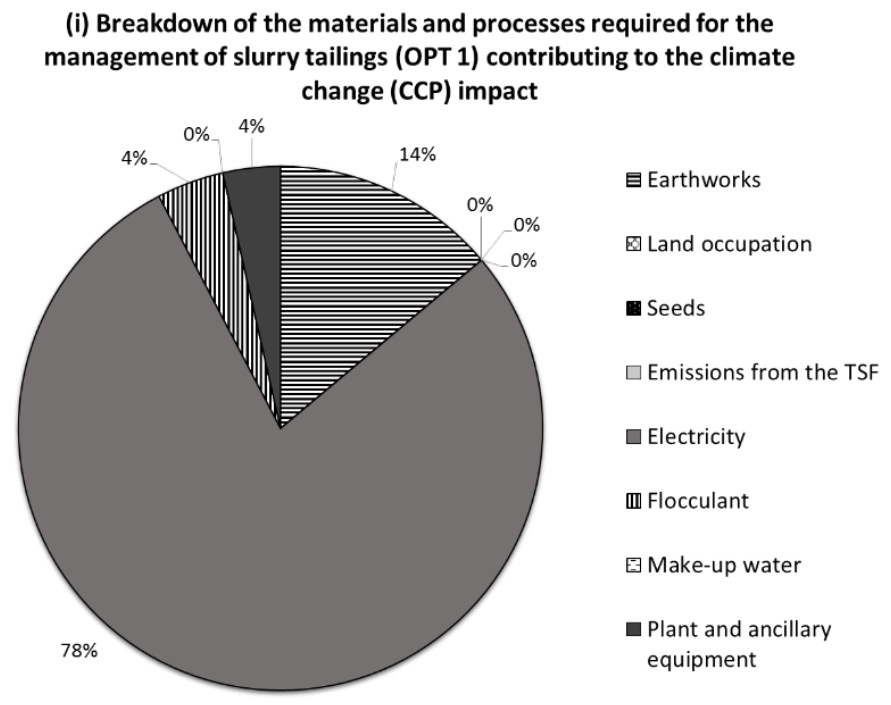

(ii) Breakdown of earthworks required throughout the LoM for the management of slurry tailings (OPT 1)

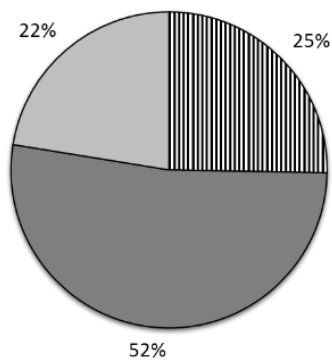

m Development phase

$\square$ Operating phase

$\square$ Closure phase (iii) Breakdown of electricity required for the

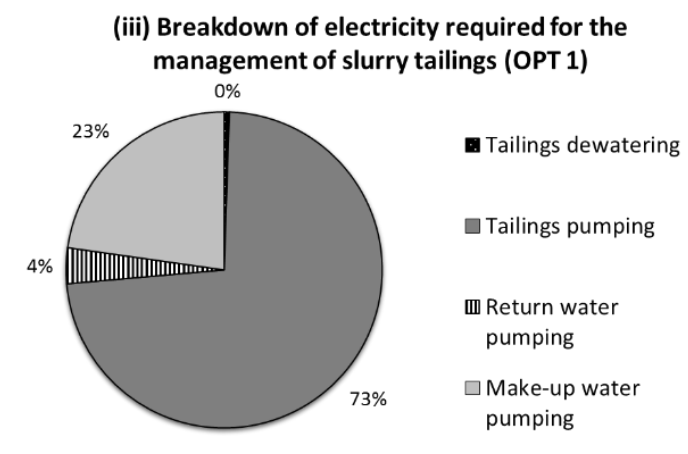

Figure 3 The relative contribution of (i) materials and processes required for tailings management on climate change impact; (ii) earthworks required in each LOM phase to the total earthworks required for tailings management; and (iii) electricity demand by different processes to the total electricity demand for tailings management 
The operation of earthmoving equipment was also found to dominate environmental impacts, contributing $76 \%$ to ozone layer depletion and $60 \%$ to the human toxicity (non-cancer) impact categories. The use of diesel in the heavy mobile equipment was found to significantly contribute to these negative impacts, with the processes associated with the production of fuel oil the main contributors to the ozone layer depletion, and the burning of diesel in dozers the primary contributor to the human toxicity (non-cancer) impact.

Overall, results of the contribution analysis indicated that the use of electricity generated by black coal, the operation of heavy diesel-powered equipment, and the onsite dust emissions from the TSF (which were found to dominate (97\%) the particulate matter formation category), are the main contributors to the potential life cycle environmental impacts of the project designed for OPT 1. Improving energy efficiency, using renewable energy to produce electricity, reducing diesel fuel consumption in earthmoving equipment and the need for earthworks for the containment of the tailings, and preventing fine-grained particles to be dispersed from the TSF, perhaps by progressively rehabilitating its side slopes throughout the LOM are therefore suggested as possible cleaner production measures to mitigate the environmental impacts of managing slurry tailings in WA.

\subsubsection{Comparison of the life cycle environmental impacts of the projects designed for the management of slurry tailings (OPT 1) and filtered tailings (OPT 2)}

Figure 4 compares the life cycle environmental impacts between the projects OPT 1 and OPT 2 (Table A3, in the Appendix). They were also estimated based on the selected midpoint impact categories drawn from four impact assessment methods recommended by the ALCAS, such as GWP, CML-IA, TRACI, and USEtox methods.

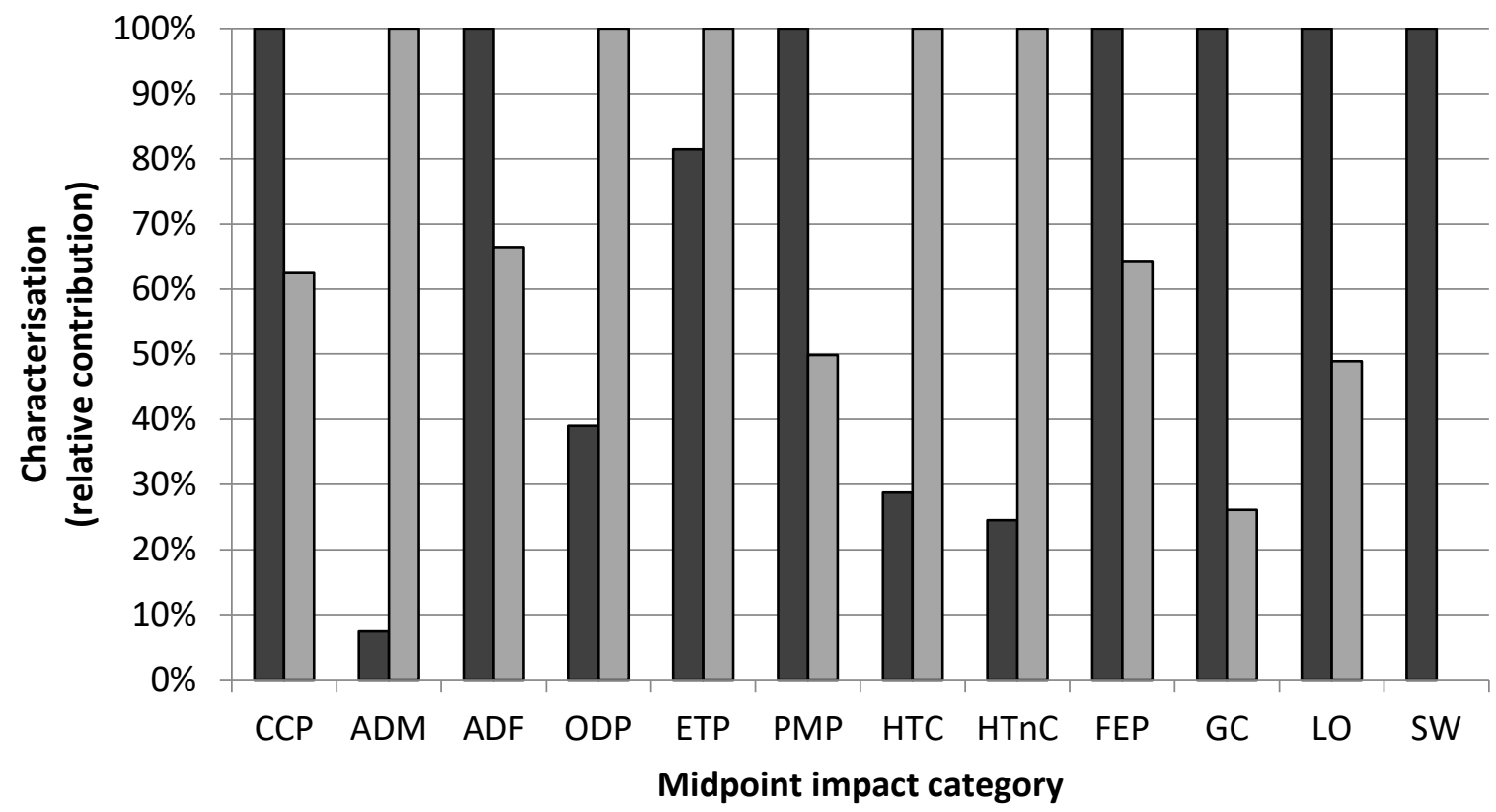

Management of slurry tailings (OPT 1) $\quad \square$ Management of filtered tailings (OPT 2)

Figure 4 Comparison of the life cycle environmental impacts between OPT 1 and OPT 2 based on selected midpoint impact categories drawn from four impact assessment methods (GWP, CML-IA, TRACl, and USEtox) ${ }^{\mathrm{a}}$. ${ }^{\mathrm{a}} \mathrm{CCP}=$ climate change; $A D M=$ mineral resource depletion; $A D F=$ fossil fuel depletion; $\mathrm{ODP}=$ ozone layer depletion; $\mathrm{ETP}=$ eutrophication; $\mathrm{PMP}=$ particulate matter formation; $\mathrm{HTC}=$ human toxicity (cancer); $\mathrm{HTnC}=$ human toxicity (non-cancer); $\mathrm{FEP}=$ freshwater ecotoxicity; $\mathrm{GC}=$ groundwater consumption; $\mathrm{LO}=$ land occupation; $\mathrm{SW}=$ seepage from the TSF 
For display purposes, the graph in Figure 4 also included three LCl metrics that are relevant in the context of this comparative LCA study involving different tailings management options. In particular, groundwater consumption, land occupation, and seepage from the TSF were included as they are representative of major concerns that can be managed at the tailings operation level to mitigate local environmental problems associated with tailings management in the Goldfields of WA.

Compared to OPT 1, the environmental impacts of OPT 2 are lower in four of the nine assessed midpoint impact categories, reducing the climate change potential by $38 \%$, depletion of fossil fuels by $34 \%$, particulate matter formation by $50 \%$, and the freshwater ecotoxicity impact by $36 \%$. It is important to highlight that the reduction of the climate change potential achieved with the replacement of fossil fuels by a renewable resource (solar energy) to generate electricity needed in the project does not represent the upper bound for the reduction on the GHG emissions that can be achieved with solar technologies. The substitution of dieselpowered earthmoving equipment with electric vehicles, which can be powered by solar energy is another interesting mitigation option, and particularly attractive for the energy-intensive mine sites located in arid climate zones of WA.

In addition, OPT 2 reduced groundwater consumption by $74 \%$, land occupation by $51 \%$, onsite dust emissions by $50 \%$, and resulted in no seepage from the TSF, according to the assumptions made for this specific case study. These are key inventory metrics that need to be managed to ensure sound environmental and social performance of mining operations, and represent significant negative project impacts that may affect a mining company's ability to secure and maintain a social licence to operate (Moffat \& Zhang 2014). The benefits of the progressive rehabilitation of the dry stack may, furthermore reduce the risks of potential local environmental impacts in the future, and improve the outcomes of TSF rehabilitation as various reclamation options can be trialled against completion criteria before closure. Also, the fact that no seepage will be expected from the dry stack presents another relevant environmental benefit. In the Goldfields of WA, a great risk to potential environmental impacts on groundwater resources relates to the elevation of the naturally saline water table as a consequence of seepage from TSFs, due to the permeable nature of certain types of tailings and the foundation soils underlying the tailings deposits. The rise in groundwater levels can result in waterlogging, vegetation decline and salinisation of the soil, affecting the surrounding ecosystems.

Increased environmental impacts were, however realised for OPT 2 in five of the nine assessed midpoint impact categories. Mineral depletion increased by $93 \%$ due to a higher demand for minerals to manufacture the PV solar panels, while the eutrophication impact increased by $19 \%$ as a result of the disposal of sulfidic tailings associated with the production of copper needed in the electricity distribution networks, as more energy will be required for processing and transporting the filtered tailings. The human toxicity (cancer) impact also increased by $71 \%$ due to the disposal of slag from the steel-making process, as more steel will be needed for manufacturing plant and ancillary equipment, and the metallic structures that will support the filtration plant building and the conveyor belt system.

The placement of filtered tailings in the dry stack area by a dozer, which will be operated for a period almost five times longer throughout the operating LOM of OPT 2 when compared to OPT 1, also contributed to the increased environmental impacts of OPT 2. The ozone layer depletion impact, for which the processes associated with the production of diesel were found as the main contributors, increased by $61 \%$, while likewise the human toxicity (non-cancer) impact increased by $76 \%$ as more diesel will be burned in the dozers.

The results of this comparative LCA study indicated, therefore that the environmental benefits of adopting technology improvements for the dewatering and transport of the tailings and renewable energy still depend on ensuring that the environmental impacts of their implementation do not result in an equal or greater increase elsewhere, including the upstream supply chain. To make better environmental decisions on a strategy for tailings management, the impacts of the products and processes required for the tailings project need to be assessed from a life cycle perspective, and mitigated. Given the extent to which water abstraction, disturbance of natural land, contamination of groundwater resources, and onsite dust emissions affect the local environment, it can be concluded that it is imperative to develop solutions to reduce the impacts of the 
upstream processes associated with the production of materials and energy needed for managing filtered tailings, so its benefits can be realised.

\section{$4 \quad$ Discussion on the challenges and benefits of adopting the life cycle assessment methodology as a decision-support tool for the evaluation of tailings management options}

In light of the importance of integrating sustainable development principles in tailings management, using LCA to systematically evaluate the environmental impacts of tailings projects from a life cycle perspective is essential to achieve optimal sustainability performance goals. The direction that the mining industry should head to become more sustainable coincides with the purpose of applying a life cycle approach and thinking. Although the LCA methodology does not hold the panacea to all of the sustainability issues faced by the mining industry, it offers a valuable concept that helps to put logic, traceability, and accountability on the environmental issues associated with its operations (Balanay \& Halog 2017). However, despite valuable features, capabilities, and advantages, the LCA methodology suffers from some limitations, and presents LCA practitioners in the minerals industry with a number of challenges that may be the possible reasons for the lack of its widespread application in decision-making.

LCA is a data hungry tool, and one of the most challenging tasks to conduct a mining LCA is to gather all the applicable information needed for compiling a LCl, which is the base of a LCA study (Durucan et al. 2006; van Zyl 2008; Reid et al. 2009; Edraki et al. 2014). Moreover, obtained input/output data and environmental information may not necessarily be complete nor absolutely objective or fully accurate due to the limited amount and quality of the information accessible (Reid et al. 2007), and because data in a format that is useful in the context of LCA are often confidential (Durucan et al. 2006). Compounding these challenges, the various sources that information is collected from and the assumptions made for preparing the inventories contribute to the issues associated with data quality and the uncertainties of the LCA results. Also, although the standardisation process reduces the uncertainties, some important methodological choices remain free to be made in each study (Reid et al. 2007). Therefore, the LCA results are dependent on subjective decisions such as the choice of time perspective, the allocation of environmental burdens, the inclusion and exclusion of processes in the study, and the approach for modelling environmental impacts.

Another limitation of the LCA methodology that might be one of the reasons why LCA is not yet extensively adopted as a decision-support tool in tailings management relates to the impact categories commonly assessed in LCAs. Although published mining LCA studies have adopted some of the same impact categories as the LCA studies performed in other industries, such as climate change, ozone layer depletion, and eutrophication potential, it is recognised that these standard impact categories are not enough to describe the environmental impacts of mining (Awuah-Offei \& Adekpedjou 2011). Land-, water-, and energy-use impacts, such as disturbance of natural land, water abstraction, groundwater resources contamination by seepage and metals leaching from TSFs are equally important in mining LCAs. These local environmental impacts play an important role in determining the overall sustainability performance of mining operations, and should be considered as relevant impact categories to be included in the scope of mining LCA studies.

Nonetheless, these challenges should not be barriers to the use of LCA as it can be considered as one of the best emerging approaches for globally assessing the environmental impacts of a project (Reid et al. 2007). Furthermore, there may be a potential to combine the results of LCA studies with the Environmental Impact Assessment (EIA) process (Tukker 2000; Manuilova et al. 2009), and integrate the LCA methodology with social and economic factors for the purpose of widening its informative framework and application. For instance, the concept of the eco-costs can be applied to the results of an LCA study to estimate the environmental costs (or 'external costs' in environmental economics terms) of the product or service under study. The eco-costs are the costs of the environmental burden of a product, process or activity on the basis of prevention of that burden. They are the costs which should be incurred for reducing the environmental pollution and materials depletion in the world to a level which is in line with the carrying capacity of the Earth (the 'no effect level') (Delft University of Technology 2017). Therefore, in addition to providing a mining 
company with insightful information about its environmental impacts and where the opportunities to improve its operational performance are, together with other life cycle approaches (e.g. life cycle costing, social life cycle assessment (SLCA), and SUSOP (SUStainable OPerations)), the LCA methodology can serve to enable decision makers to decide on the best practice for tailings disposal efficiency to ensure sound environmental, social and economic performance.

\section{Conclusion}

A cradle-to-grave LCA study was carried out to investigate the environmental profiles of two tailings management options; OPT 1 involving the disposal of slurry tailings and OPT 2 involving the disposal of filtered tailings, which will be transported to the TSF by an electric conveyor belt system, and all the electricity needed for tailings management will be supplied by solar energy. This was done to examine whether the adoption of technology improvements for the dewatering and transport of the tailings and renewable energy affect the environmental performance of the tailings operation.

The results of a process contribution analysis showed the use of electricity generated by coal-fired plants, the operation of diesel-powered equipment to perform earthworks, and the dispersion of fine-grained particles from the TSF are the key contributors to the environmental impacts of OPT 1. Therefore, improving energy efficiency, using renewable energy to produce electricity, reducing diesel fuel consumption in earthmoving equipment and the need for earthworks for the containment of the tailings and preventing dust emissions from the TSF, perhaps by progressively rehabilitating its side slopes throughout the LOM were suggested as possible cleaner production measures to mitigate the environmental impacts of managing slurry tailings in WA.

A comparison of the environmental profiles of OPT 1 and OPT 2 revealed that managing filtered tailings reduced the environmental impacts in four of the nine midpoint impact categories assessed in this study, particularly reducing climate change (38\%). In addition, OPT 2 reduced groundwater consumption by $74 \%$, land occupation by $51 \%$, and onsite dust emissions by $50 \%$. However, the use of solar energy increased mineral depletion by $93 \%$ due to the use of minerals to manufacture PV solar panels, and the need for a filtration plant for tailings processing increased the human toxicity (cancer) impact by $71 \%$, attributed to the disposal of slag from the steel-making process. The continuous placement of filtered tailings in the dry stack area by a dozer throughout the LOM also contributed to higher environmental impacts, resulting in an increase of $61 \%$ in the ozone layer depletion and $76 \%$ in the human toxicity (non-cancer) impact categories.

There are two main conclusions to be drawn from the discussion presented in this paper. Firstly, efforts to reduce the environmental impacts of managing tailings should focus on reducing the environmental impacts of the upstream processes required for tailings management, such as those needed for steel-making and solar energy generation. Provided these are assessed from a life cycle perspective and mitigated where possible, and given the lower environmental impacts on a local scale expected for OPT 2, the management of filtered tailings may be the most sustainable option for this specific case study.

Secondly, given the importance of applying life cycle approaches to the evaluation of tailings management options the LCA methodology is suggested as offering a valuable tool for quantifying the environmental issues associated with tailings operations that rationally incorporates logic, traceability and accountability. In the future, the integration of environmental risks (e.g. dispersion of contaminants from the TSF and catastrophic tailings dam failures) into the assessment of tailings project options will become more prominent, particularly as external pressures force mining operators to improve mine waste management and reduce environmental impacts.

\section{Acknowledgement}

This paper presents part of the results of a project financially supported by The University of Western Australia and the Australian Centre for Geomechanics. The paper benefitted from fruitful discussions with researchers and industry professionals; these are gratefully acknowledged. 


\section{Appendix}

Table A1 Main assumptions made for the development of the life cycle inventories of the tailings management options assessed in this LCA study

\begin{tabular}{|c|c|}
\hline Item & Assumptions \\
\hline $\begin{array}{l}\text { Operation of } \\
\text { haulage trucks }\end{array}$ & $\begin{array}{l}\text { A unit process associated with the operation of a } 28 \mathrm{t} \text { truck was modified to have } \\
\text { similar characteristics of a } 98 \mathrm{t} \text { mining haulage truck, which was assumed to weigh } \\
56,428 \mathrm{~kg} \text {, and be able to haul } 480 \mathrm{~m}^{3} / \mathrm{h} \text { with a diesel consumption of } 0.9 \mathrm{~L} / \mathrm{km} \text {. }\end{array}$ \\
\hline $\begin{array}{l}\text { Construction } \\
\text { material }\end{array}$ & $\begin{array}{l}\text { Construction material needed for building the TSF and associated infrastructure was } \\
\text { assumed to have a density of } 2.65 \mathrm{t} / \mathrm{m}^{3} \text {, and to be hauled for a distance of } 5 \mathrm{~km} \text {. }\end{array}$ \\
\hline $\begin{array}{l}\text { Operation of } \\
\text { dozers }\end{array}$ & $\begin{array}{l}\text { A productivity } 450 \mathrm{~m}^{3} / \mathrm{h} \text { was assumed for the dozer required for the earthworks } \\
\text { associated with material handling. A unit process (available in the Aus } \mathrm{LCl} \text { library in } \\
\text { SimaPro 9.0.0.35) associated with the operation of a bulldozer in Australia was } \\
\text { considered. }\end{array}$ \\
\hline Flocculant & $\begin{array}{l}\text { A unit process associated with the production of polyacrylamide was assumed as } \\
\text { representative of the process of producing the flocculant. Its transport to the mine } \\
\text { site was also considered. }\end{array}$ \\
\hline Filter cloths & $\begin{array}{l}\text { It was considered } 21 \mathrm{~kg} \text { of polypropylene per filter cloth, which was assumed to be } \\
\text { changed after completing } 4,000 \text { cycles of } 20 \text { minutes each. }\end{array}$ \\
\hline Seepage & $\begin{array}{l}\text { Seepage was assumed from the TSF designed for the management of slurry tailings. } \\
\text { It was estimated as } 10 \% \text { of the total volume of water discharged with the tailings. }\end{array}$ \\
\hline Dust emissions & $\begin{array}{l}\text { A linear relationship between dust emissions and the slanted lateral surface area of } \\
\text { the TSF was assumed. A wind erosion rate of } 25(\mathrm{t} / \mathrm{y}) / \text { ha over the operating phase of } \\
\text { the project was considered (Blight 2008). Released particles to air were assumed to } \\
\text { be } 5 \% \text { particulate matter }(\mathrm{PM})<2.5,45 \% 2.5<\mathrm{PM}<10 \text { and } 50 \% \mathrm{PM}>10 \text { (Song et al. } \\
\text { 2017). }\end{array}$ \\
\hline $\begin{array}{l}\text { Transport } \\
\text { distance }\end{array}$ & $\begin{array}{l}\text { An average distance of } 600 \mathrm{~km} \text { was assumed for the transport of materials and plant } \\
\text { equipment to the mine site. }\end{array}$ \\
\hline Make-up water & $\begin{array}{l}\text { Make-up water was assumed to be sourced from groundwater resources, and has a } \\
\text { density of } 1.08 \mathrm{t} / \mathrm{m}^{3} \text { (hypersaline water). }\end{array}$ \\
\hline Seeds & A seeding rate of $9 \mathrm{~kg} / \mathrm{ha}$ was assumed for the revegetation of the disturbed areas. \\
\hline
\end{tabular}




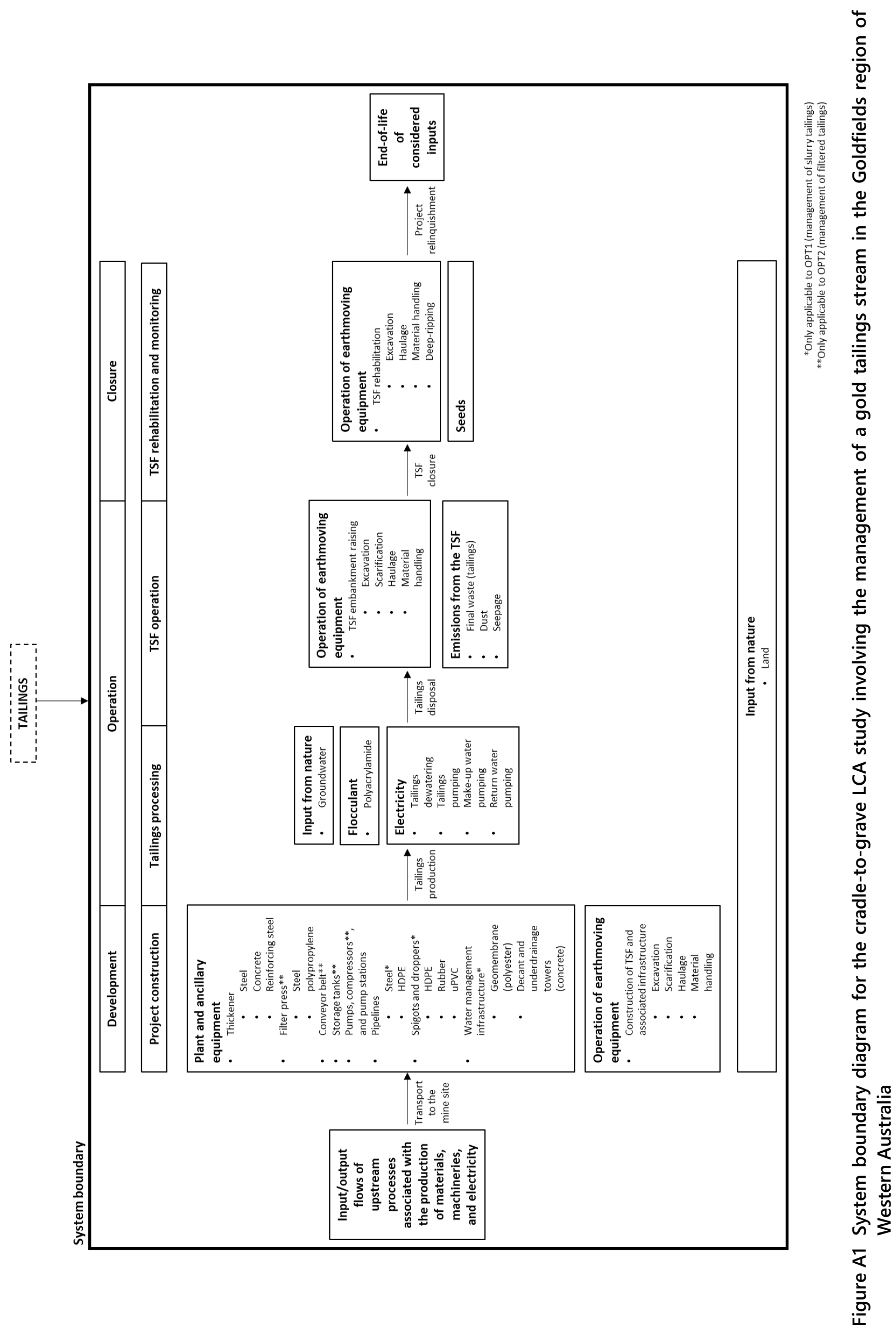




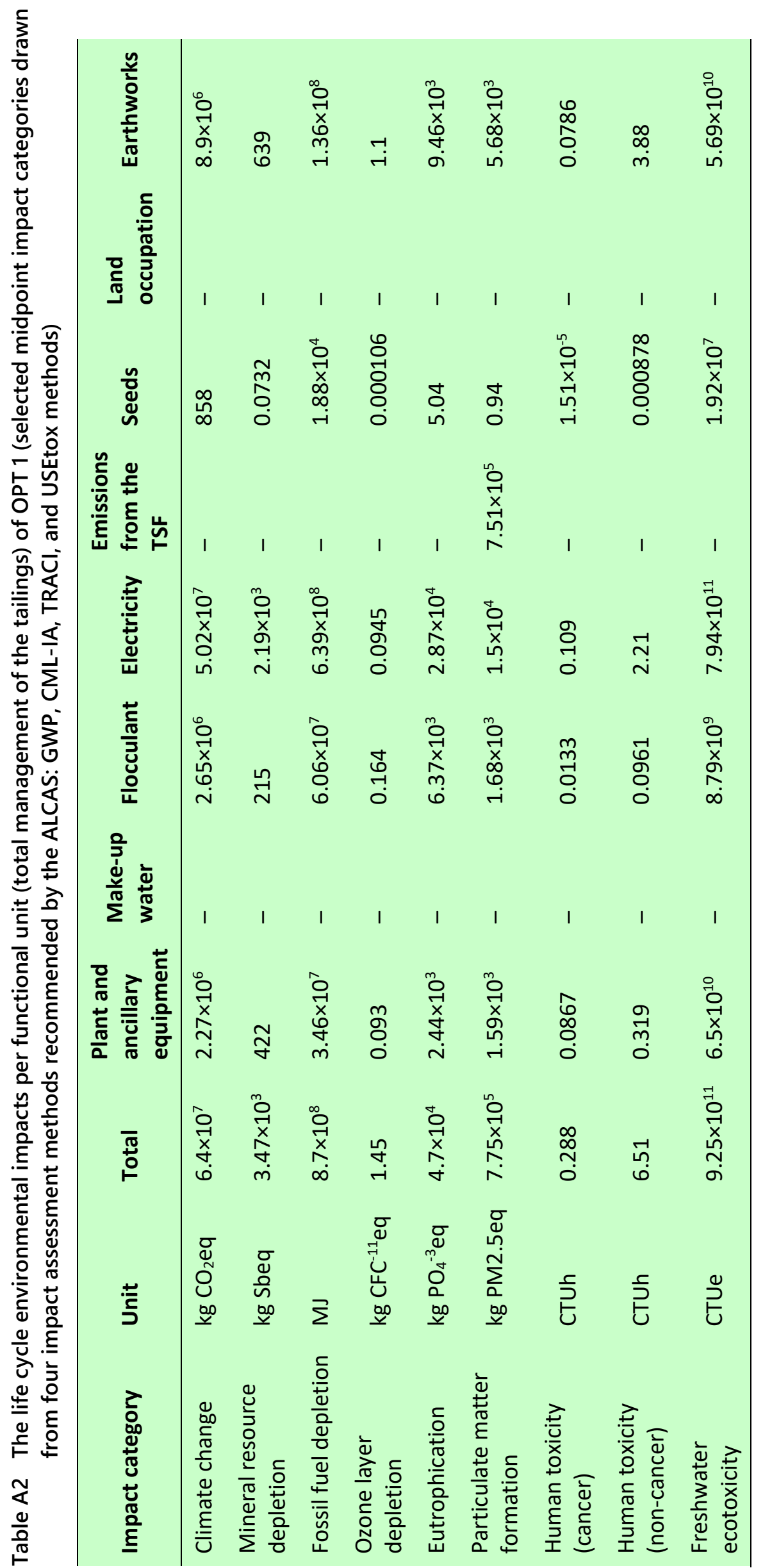




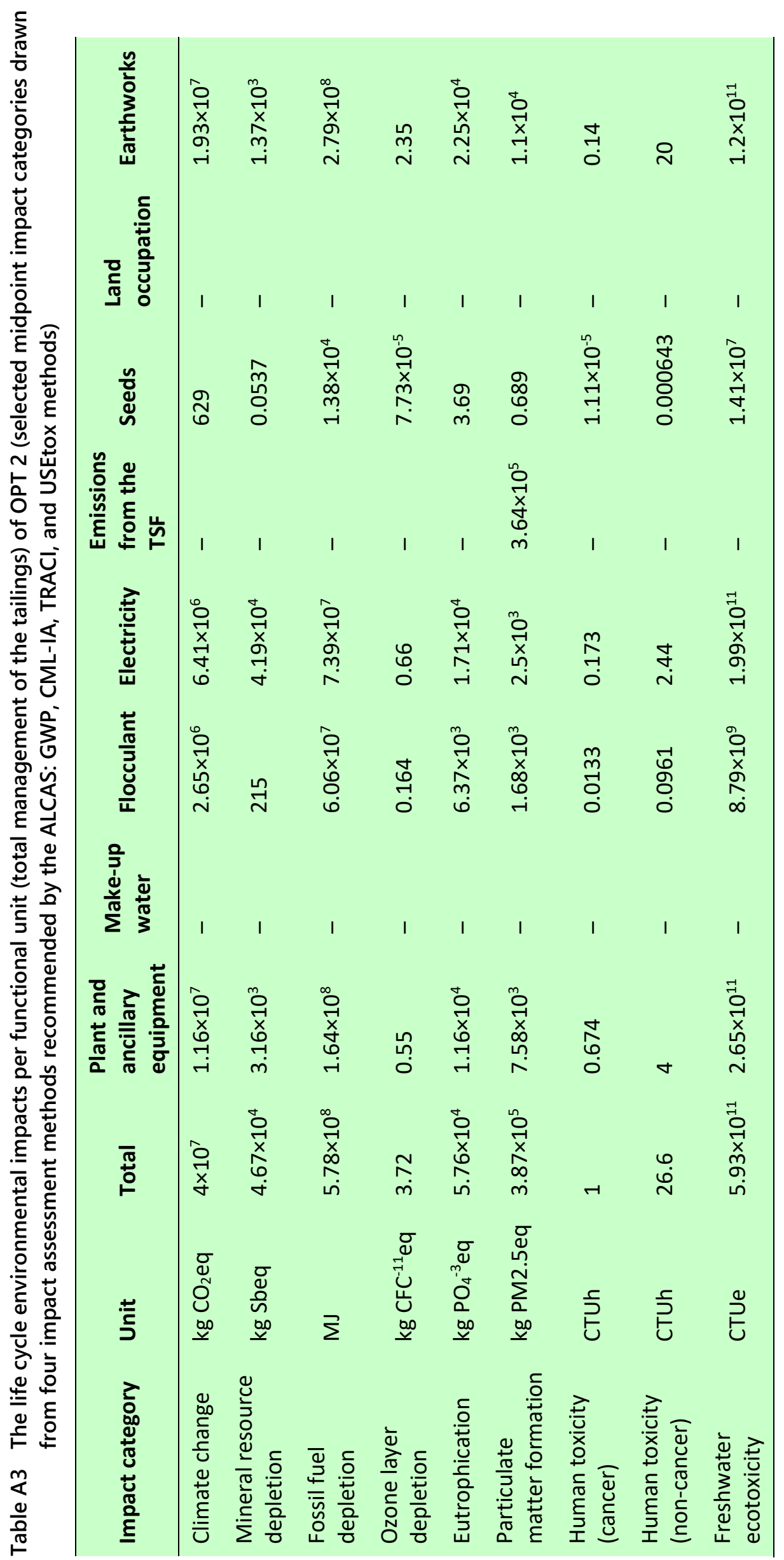




\section{References}

Adiansyah, JS, Haque, N, Rosano, M \& Biswas, W 2017, 'Application of a life cycle assessment to compare environmental performance in coal mine tailings management', Journal of Environmental Management, vol. 199, pp. 181-191.

Awuah-Offei, K \& Adekpedjou, A 2011, 'Application of life cycle assessment in the mining industry', The International Journal of Life Cycle Assessment, vol. 16, pp. 82-89.

Awuah-Offei, K, Checkel, D \& Askari-Nasab, H 2009, 'Evaluation of belt conveyor and truck haulage systems in an open pit mine using life cycle assessment', CCIM Bulletin, p. 1116.

Balanay, RM \& Halog, A 2017, 'Promoting life cycle thinking for sustainability in the mining sector of the Philippines', The International Journal of Life Cycle Assessment, vol. 22, pp. 1864-1874.

Bare, JC 2002, 'TRACI - The Tool for the Reduction and Assessment of Chemical and Other Environmental Impacts', Journal of Industrial Ecology, vol. 6, pp. 49-78.

Blight, GE 2008, 'Wind erosion of waste impoundments in arid climates and mitigation of dust pollution', Waste Management \& Research, vol. 26, pp. 523-533.

Carneiro, A \& Fourie, AB 2017, 'Economic evaluation for the disposal of slurry versus thickened tailings in Western Australia - A case study', in GW Wilson, DC Sego \& NA Beier (eds), Proceedings of the Twenty-first International Conference on Tailings and Mine Waste, University of Alberta Geotechnical Centre, Edmonton, pp. 138-149.

Carneiro, A \& Fourie, AB 2018, 'A conceptual cost comparison of alternative tailings disposal strategies in Western Australia', in RJ Jewell \& AB Fourie (eds), Proceedings of the 21st International Seminar on Paste and Thickened Tailings, Australian Centre for Geomechanics, Perth, pp. 439-454.

Carneiro, A \& Fourie, AB 2019, 'An integrated approach to cost comparisons of different tailings management options', in AB Fourie, AJC Paterson \& D Reid (eds), Proceedings of the 22nd International Seminar on Paste, Thickened and Filtered Tailings, Australian Centre for Geomechanics, Perth, pp. 113-124.

Delft University of Technology 2017, The Model of the Eco-costs/Value Ratio (EVR), viewed 24 March 2019, http://www.ecocostsvalue.com/EVR/model/theory/subject/2-eco-costs.html

Dong, Y, Miraglia, S, Manzo, S, Georgiadis, S, Sørup, HJD, Boriani, E, Hald, T, Thöns, S \& Hauschild, MZ 2018, 'Environmental sustainable decision making - The need and obstacles for integration of LCA into decision analysis', Environmental Science \& Policy, vol. 87, pp. 33-44.

Durucan, S, Korre, A \& Munoz-Melendez, G 2006, 'Mining life cycle modelling: a cradle-to-gate approach to environmental management in the minerals industry', Journal of Cleaner Production, vol. 14, pp. 1057-1070.

Edraki, M, Baumgartl, T, Manlapig, E, Bradshaw, D, Franks, DM \& Moran, CJ 2014, 'Designing mine tailings for better environmental, social and economic outcomes: a review of alternative approaches', Journal of Cleaner Production, vol. 84, pp. 411-420.

Erkayaoğlu, M \& Demirel, N 2016, 'A comparative life cycle assessment of material handling systems for sustainable mining', Journal of Environmental Management, vol. 174, pp. 1-6.

Espinoza, RD \& Morris, JWF 2017, 'Towards sustainable mining (part II): accounting for mine reclamation and post reclamation care liabilities', Resources Policy, vol. 52, pp. 29-38.

Grant, T 2016, AusLCl database manual, viewed 15 March 2019, http://auslci.com.au/Documents/AUSLCI_Manual\%20V1.26.pdf

Guinée, JB 2002, Handbook on Life Cycle Assessment - Operational Guide to the ISO Standards, https://www.springer.com/gp/book/9781402002281

International Council on Mining and Metals 2016, Position statement on preventing catastrophic failure of tailings storage facilities, viewed 1 October 2018, https://www.icmm.com/website/publications/pdfs/commitments/2016_icmm-ps_tailingsgovernance.pdf

International Organization for Standardization 2006a, ISO 14040:2006 Environmental Management - Life Cycle Assessment Principles and Framework, https://www.iso.org/obp/ui/\#iso:std:iso:14040:ed-2:v1:en

International Organization for Standardization 2006b, ISO 14044:2006 Environmental Management - Life Cycle Assessment Requirements and Guidelines, https://www.iso.org/obp/ui/\#iso:std:iso:14044:ed-1:v1:en

Kounina, A, Margni, M, Shaked, S, Bulle, C \& Jolliet, O 2014, 'Spatial analysis of toxic emissions in LCA: A sub-continental nested USEtox model with freshwater archetypes', Environment International, vol. 69, pp. 67-89.

Manuilova, A, Suebsiri, J \& Wilson, M 2009, 'Should Life Cycle Assessment be part of the Environmental Impact Assessment? Case study: EIA of CO2 Capture and Storage in Canada', Energy Procedia, vol. 1, pp. 4511-4518.

Moffat, K \& Zhang, A 2014, 'The paths to social licence to operate: An integrative model explaining community acceptance of mining', Resource Policy, vol. 39, pp. 61-70.

Norgate, T \& Haque, N 2010, 'Energy and greenhouse gas impacts of mining and mineral processing operations', Journal of Cleaner Production, vol. 18, pp. 266-274.

PRé Consultants 2019, SimaPro, version 9.0.0.35, computer software, PRé Consultants, Amersfoort, https://simapro.com

Reid, C, Aubertin, M, Deschênes, L, Bussière, B \& Bécaert, V 2007, 'Application of life cycle assessment (LCA) to sulphidic tailings management', Proceedings of the Mining and the Environment IV Conference, Sudbury, pp. 19-27.

Reid, C, Bécaert, V, Aubertin, M, Rosenbaum, RK \& Deschênes, L 2009, 'Life cycle assessment of mine tailings management in Canada', Journal of Cleaner Production, vol. 17, pp. 471-479.

Renouf, MA, Grant, T, Sevenster, M, Logie, J, Ridoutt, B, Ximenes, F, ... Lane, J 2018, Best Practice Guide for Mid-Point Life Cycle Impact Assessment in Australia, viewed 15 March 2019, in http://www.auslci.com.au/Documents/Best_Practice_ Guide_V2_13_4_18.pdf 
Solomon, S, Qin, D, Manning, M, Averyt, K \& Marquis, M 2007, Climate change 2007 - the physical science basis: Working group I contribution to the fourth assessment report of the IPCC, Cambridge University Press, Cambridge.

Song, X, Pettersen, JB, Pedersen, KB \& Røberg, S 2017, 'Comparative life cycle assessment of tailings management and energy scenarios for a copper ore mine: A case study in Northern Norway', Journal of Cleaner Production, vol. 164, pp. 892-904.

Tukker, A 2000, 'Life cycle assessment as a tool in environmental impact assessment', Environmental Impact Assessment Review, vol. 20, pp. 435-456.

van Zyl, D 2008, 'Life cycle assessment and tailings management trade-off studies - concepts', Proceedings of the Eighth International Conference on Tailings and Mine Waste, pp. 355-358. 
